\title{
PREVALENCE OF THE METABOLIC SYNDROME AMONG PATIENTS WITH TYPE 2 DIABETES MELLITUS IN UYO, NIGERIA
}

\author{
UNADIKE BC', AKPAN NA', PETERS EJ ${ }^{2}$, ESSIEN I O', ESSIEN OE ${ }^{2}$ \\ Department of Internal Medicine \\ University of Uyo Teaching Hospital, Uyo, Akwa Ibom State \\ Department of Medicine \\ University of Calabar Teaching Hospital, Calabar, Cross River state \\ *Corresponding author \\ E-mail: bernadike@yahoo.com
}

\begin{abstract}
Background: The metabolic syndrome is a cluster of risk factors that is responsible for most of the excess cardiovascular morbidity amongst persons with type 2 Diabetes Mellitus (DM). The metabolic syndrome increases the risk for coronary heart disease and stroke by three-fold with a marked increase in cardiovascular mortality.

Objectives: This study set out to find the prevalence of the metabolic syndrome amongst type 2 diabetes mellitus patients and the commonest metabolic abnormalities in them in Uyo, South-South Nigeria.

Subjects and Methods: A prospective cross sectional study carried out at the diabetes clinic of the University of Uyo Teaching Hospital, between January and August, 2008. Data obtained included anthropometric indices, blood pressure and fasting serum lipids. Data was analyzed using SPSS version 10.

Results: Two hundred and forty subjects (106 males, 134 females) were enrolled for the study. The prevalence of metabolic syndrome was

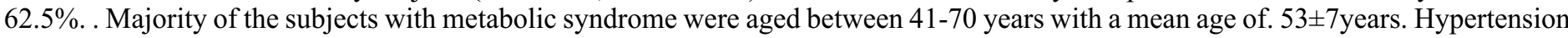
was the most common metabolic abnormality present in $130(86.6 \%)$ of the subjects with metabolic syndrome, while low high density lipoprotein (HDL) was the least common abnormality present in $26(17.3 \%)$ of the subjects with metabolic syndrome. Two metabolic abnormalities were present in $114(76 \%)$ of the subjects, while four abnormalities were present in $4(2.6 \%)$ of the subjects with metabolic syndrome.

Conclusion: The prevalence of metabolic syndrome in type 2 DM patients in Uyo, South-South of Nigeria is high. With the cardiovascular risk associated with this syndrome, efforts must be geared towards addressing these abnormalities through lifestyle modification, health awareness and medications in order to reduce this complication in type $2 \mathrm{DM}$ patients.
\end{abstract}

Keywords: Metabolic syndrome, Type 2 DM, Uyo.

\section{INTRODUCTION}

Type 2 Diabetes Mellitus is a heterogeneous metabolic disorder characterized by chronic hyperglycemia due to dynamic interactions between varying degrees of insulin secretion and insulin resistance. Either of these defects may be the predominant feature in a particular case (1-4). The metabolic syndrome, also called insulin resistance syndrome or syndrome $X$, is a cluster of risk factors that is responsible for much of the excess cardiovascular disease morbidity amongst overweight and obese patients and those with type 2 Diabetes Mellitus (5).

The metabolic syndrome is defined when three or more of the following are present (6):

Abdominal obesity with waist circumference for men $>102 \mathrm{~cm}$ and women $>88 \mathrm{~cm}$.

Serum Triglyceride $>1.7 \mathrm{mmol} / 1$.

High density, lipoprotein (HDL) cholesterol for men $<0.9 \mathrm{mmol} / 1$ and for women $<1.0 \mathrm{mmol} / 1$.

Blood pressure $>130 / 85 \mathrm{mmHg}$.

Fasting plasma glucose $>110 \mathrm{mg} / \mathrm{dl}$.

The importance of the metabolic syndrome lies in the fact that each individual component carries a grave risk for vascular events and the combination has a synergistic effect (7).

This study therefore set out to find the prevalence of metabolic syndrome amongst persons with type $2 \mathrm{DM}$, and the commonest metabolic abnormality in these persons and to compare this with findings elsewhere where such studies have been done.

\section{SUBJECTS AND METHODS}

This was a cross sectional, prospective study carried out at the Diabetes clinic of the University of Uyo Teaching Hospital. The study was carried out between January and August, 2008. Informed consent was obtained from the subjects after the study guidelines had been explained to them. Patients who were not more than 70 years of age, and have had type $2 \mathrm{DM}$ for not less than 6 months were enrolled for the study. A brief clinical history was obtained from the subjects while anthropometric indices and blood pressure was measured. Weight in kilogrammes and height in metres was obtained from the weighing scale and stadiometer, respectively. The waist circumference was taken as the midpoint between the rib cage and iliac crest while hip circumference was taken as the maximal circumference around the buttocks posteriorly and pubic symphysis anteriorly (8). Blood pressure was measured in the sitting position with a mercury sphygmomanometer and hypertension diagnosed if patient has been on antihypertensive drugs, or had a blood pressure reading of $>130 \mathrm{mmHg}$ systolic and/or diastolic blood pressure of $>85 \mathrm{mmHg}$. Serum lipids were taken after at least an 8 hour fast. Metabolic syndrome was diagnosed using the ATP criteria $(5,6)$. Since all the patients were diabetic, the presence of two metabolic abnormalities other than diabetes was enough to establish the diagnosis of metabolic syndrome. Data analysis was done using SPSS version 10 and results were presented in a tabulated form. The level of statistical significance was taken as $p \mathrm{~d}$ '0.05. 


\section{RESULTS}

A total of two hundred and forty subjects were enrolled for the study. These were one hundred and six (106) males and one hundred and thirty four (134) females giving a male: female ratio of $1: 1.2$. The mean age of the study subjects was $50.8 \pm 11$ years. One hundred and fifty (150) persons had metabolic syndrome giving a prevalence of $62.5 \%$. The mean age of the subjects with metabolic syndrome was $53 \pm 7$ years (table 1), the mean body mass index was $28.7 \pm 6.4 \mathrm{~kg} / \mathrm{m}^{2}$ while the mean waist hip ratio was $0.94 \pm 0.08$. This is shown in table 1 . There were forty-four males and one hundred and six females with metabolic syndrome giving a male: female ratio of 1:2.4. Majority of the subjects $(77.3 \%)$ were aged between $41-70$ years. The age distribution is shown in table 2 . Fifty four $(36 \%)$ of subjects with metabolic syndrome had generalized obesity, while $102(72 \%)$ were centrally obese using waist circumference, and $1.6(84 \%)$ using waist hip ratio. The age distribution of the subjects with metabolic syndrome is shown in table 2.

Hypertension was the commonest metabolic abnormality present in $86.6 \%$ of the subjects, while low HDL cholesterol was the least common abnormality present in $17.3 \%$ of the subjects. The distribution of the metabolic abnormalities is shown in table 3. Two metabolic abnormalities were present in 114 (76\%) subjects; three abnormalities in $22(14.6 \%)$ subjects while only $4(2.6 \%)$ subjects had four metabolic abnormalities.

Table 1: Clinical Characteristics of subjects with metabolic syndrome $(n=150)$

\begin{tabular}{ll}
\hline Parameter & Mean \pm SD \\
\hline Age $($ years $)$ & $53 \pm 7$ \\
BMI $\left(\mathrm{kg} / \mathrm{m}^{2}\right)$ & $28.7 \pm 6.4$ \\
WHR & $0.94 \pm 0.08$ \\
& \\
BMI: & Body Mass Index \\
WHR: & Waist hip ratio \\
\hline
\end{tabular}

Table 2: Age and distribution of patients with metabolic syndrome

\begin{tabular}{ll}
\hline Age & No(\%) \\
\hline$<30$ & $2(1.33)$ \\
$31-40$ & $32(21.3)$ \\
$41-50$ & $38(25.3)$ \\
$51-60$ & $40(26.6)$ \\
$61-70$ & $38(25.3)$ \\
\hline
\end{tabular}

Table 3: Prevalence of different components of the metabolic Syndrome amongst Type $2 \mathrm{DM}$ patients

\begin{tabular}{llll}
\hline $\begin{array}{l}\text { Metabolic } \\
\text { Abnormality }\end{array}$ & Men & Women & Total \\
\hline Hypertension & 44 & 86 & 130 \\
High Triglyceride & 32 & 40 & 72 \\
Abdominal Obesity & 12 & 100 & 112 \\
Low HDL & 12 & 14 & 26 \\
\hline
\end{tabular}

* Hypertension: $>130 / 85 \mathrm{mmHg}$

* High Triglyceride: $>1.7 \mathrm{mmol} / 1$

*Abdominal Obesity Male: $>102 \mathrm{~cm}$,

Female: $>88 \mathrm{~cm}$

* Low HDL Male: $<0.9 \mathrm{mmol} / 1$

Female: $<0.1 \mathrm{mmol} / 1$

HDL: High density lipoprotein

\section{DISCUSSION}

The metabolic syndrome is a complex combination of entities including abdominal obesity, atherogenic dyslipidaemia, elevated blood pressure, insulin resistance plus glucose intolerance and a prothrombotic and proinflammatory state that affects all ages (6). This syndrome is also known as "syndrome X", "insulin resistance syndrome", the "deadly quartet", "cardiometabolic syndrome", "Reaven's syndrome" amongst others (6). Various organizations have published criteria for diagnosis of the metabolic syndrome including the World Health Organization (WHO), the National Cholesterol Education Programme (NCEP) and the American Association of Clinical Endocrinologists (AACE) $(6,9,10)$. Initially called syndrome $\mathrm{X}$ in 1988 by Reaven, each component of the syndrome has been associated with an increased risk of cardiovascular disease $(11,12)$.

The prevalence of metabolic syndrome in this study is $62.5 \%$. In similar studies amongst type 2 DM subjects in Iraq, a high prevalence rate of $86 \%$, was seen, while a lower prevalence rate of $56 \%$ was seen in patients of Saudi Arabian origin $(13,14)$. A similar study done amongst type 2 diabetes patients in Lagos, Nigeria reported a prevalence rate of $51 \%(15)$. The prevalence of the metabolic syndrome is strongly dependent on the definition that is used to diagnose the syndrome. The high prevalence in our study could be due to rapid urbanization and adoption of unhealthy lifestyle amongst our people like physical inactivity, sedentary behaviour and unhealthy dietary habits, which predispose individuals to obesity. More females than males had metabolic syndrome giving a male to female ratio of $1: 2.4$. The higher ratio of females may be due to the fact that Nigerian women seek medical attention more than their male counterparts. This is similarly reported from the study in Lagos, Nigeria (15). Majority of our subjects with metabolic syndrome were aged between 4170 years with a mean age of $53 \pm 7$ years. Metabolic syndrome prevalence increases with age. Our findings, are similar to that of Adediran et al., in which majority of those with metabolic syndrome were over 60 years with a mean age of $59 \pm 12$ years, while in the Saudi Arabian study, the mean age was $60 \pm 13$ years confirming the fact that metabolic syndrome is more common amongst the elderly $(14,15) .86 .6 \%$ of the subjects had hypertension and this was the commonest metabolic abnormality. Hypertension is an important cardiovascular risk factor on its own, and in combination with insulin resistance in these patients will have a synergistic effect and carry a grave risk for severe vascular events. Adediran et al., reported that $59 \%$ of the subject had hypertension, while Mansour reported a rate of $76 \%$ amongst subjects with metabolic syndrome in his study $(13,15)$. Low HDL was the least common metabolic abnormality seen in our study, and this was similar to the findings by Mansour in Iraq (13). The clinical importance of the metabolic syndrome is related to its putative impact on cardiovascular morbidity and mortality. In a Scandinavian study it was shown that the prevalence of coronary heart disease, myocardial infarction and stroke was approximately threefold higher in subjects with the metabolic syndrome than in those without the syndrome (14). Management of the metabolic syndrome includes dietary modification, exercise and medications which reduce insulin resistance and this will reduce the morbidity and mortality associated with this syndrome.

\section{CONCLUSION}

The metabolic syndrome is common amongst type 2 DM patients in Uyo. Efforts should be intensified in educating patients about lifestyle modifications and treatment offered to these 
patients to reduce the excess cardiovascular risk that is associated with this condition.

\section{REFERENCES}

1. World Health Organization. Definition, diagnosis and classification of Diabetes Mellitus and its Complications. Report of a WHO Consultation WHO, Geneva, 1999.

2. Martin BC, Warram JH, Krowleski AS, Bergman RN, Soeldner JS, Kahn CR. Role of glucose and insulin resistance in the development of Type 2 Diabetes Mellitus: results of a 25 year follow up study. Lancet, 1992; 340:925-929.

3. Banerji MA, Levovitz H. Insulin sensitive and insulin resistance variants in NIDDM. Diabetes, 1989; 38: 784-792.

4. Polonsky KS, Sturis J. Bell GI. Non-Insulin dependent diabetes mellitus. A genetically programmed failure of the beta cell to compensate for insulin resistance. $N$ Engl J Med, 1996; 334: 289-293.

5. Vega GL. Obesity, The Metabolic Syndrome and Cardiovascular Disease. Am Heart J, 2001; 142: 1108-1116.

6. National Institute of Health. Third Report of the National Cholesterol Education Program Expert Panel Report on Detection, Evaluation, and Treatment of High Blood Cholesterol in Adults (Adult Treatment Panel 111) Bethesda: NIH 2001.

7. Polonsky KMD, Gremel SM. Non-Insulin dependent diabetes mellitus - a genetically programmed failure of the beta cell to compensate for insulin resistance. $N$ Engl J Med, 1996; 334:777-783.

8. Bray GA. Obesity: Basic consideration and clinical Approaches. Dis Mon, 1989; 35: 449-537.

9. Insulin resistance syndrome task force. American College of Endocrinology. Endocr Pract, 2003, 9: 237-252.

10. Alberti KG, Zimmet PZ: Definition, diagnosis and classification of diabetes mellitus and its complications Part I: Diagnosis and classification of diabetes mellitus: provisional report of a WHO Consultation. Diabet Med, 1998; 15: 539-553.

11. Reaven GM: Role of Insulin resistance in human disease. Diabetes, 1988; 37: 1595-1607.

12. Anand S, Yi Q, Gerstein H, Lonn E, Jacobs R, Vaksan V, et $a l .:$ Relationship of metabolic syndrome and fibrinolytic dysfunction to cardiovascular disease. Circulation, 2003; 108: 420-425.

13. Mansour A. A. Prevalence of the Metabolic Syndrome among patients with Type 2 diabetes in Iraq. Diabetes Int, 2007; 15:12.

14. Akbar DH. Metabolic Syndrome is common in Saudi type 2 diabetic patients. Diabetes Int, 2002; 12: 47-49.

15. Adediran OS, Edo AE, Jimoh AK, Ohwovoriole A. E. Prevalence of the Metabolic Syndrome among Nigerians with type 2 diabetes. Diabetes Int, 2007; 15: 13-14. 